\title{
CAPACIDADE DE LIGAÇÃO DOS ESPERMATOZOIDES DO EPIDÍDIMO DE EQUINOS ÀS CÉLULAS DA TUBA UTERINA CULTIVADAS IN VITRO - REVISÃO DE LITERATURA
}

\author{
João Alexandre Matos Carneiro ${ }^{1}$ \\ Raíssa Karolliny Salgueiro Cruz \\ Fabiana Ferreira de Souza \\ José Antonio Dell Aqua-Júnior
}

\begin{abstract}
RESUMO
Muitas biotecnologias estão sendo desenvolvidas visando a conservação do material genético de garanhões de alto valor zootécnico. Dentre estas pode-se destacar a colheita de espermatozoides do epidídimo de animais que sofreram algum trauma ou enfermidade que impossibilitem a colheita do sêmen, óbito ou eutanásia. Porém essas células espermáticas não entram em contato com o plasma seminal, importante por conter proteínas que participam de processos relacionados à proteção e ligação dos espermatozoides aos reservatórios espermáticos na tuba uterina. Neste sentido, sugere-se que ocorram alterações bioquímicas nas células espermáticas do epidídimo. Objetivou-se com esta revisão, estudar as principais diferenças morfofuncionais entre os espermatozoides provenientes do epidídimo e do ejaculado de equinos.
\end{abstract}

Palavras-chave: espermatozoide, plasma seminal, adesão celular.

\section{CAPACITY OF BINDING FROM EQUINE EPIDIDYMIS SPERMATOZOA TO THE OVIDUCT CELLS CULTURED IN VITRO - REVIEW OF THE LITERATURE}

\begin{abstract}
Several biotechnologies are being developed aiming genetic material conservation of stallions with high zootechnical value, as we can highlight the harvest epididymis's sperm of animals who suffered trauma or illness that makes impossible the semen collection, death or euthanasia. However these sperm cells do not get in touch with seminal plasma, important whereas it has proteins that participate in processes related to the protection and binding of sperm to the sperm reservoir in the oviduct. In this sense, it suggests that there are significant biochemical changes in epididymal sperm. This review aimed to study the main morphological and functional differences between the sperm from the epididymis and ejaculated in horses.
\end{abstract}

Keywords: spermatozoon, seminal plasma, cell adhesion.

\footnotetext{
${ }^{1}$ Departamento de Reprodução Animal e Radiologia Veterinária, FMVZ-UNESP-Botucatu. Distrito de Rubião Júnior S/N, 18618970. Contato correspondência.

Carneiro JAM, Cruz RKS, Souza FF, Dell'Aqua Junior JA. Capacidade de ligação dos espermatozoides do epidídimo de equinos às células da tuba uterina cultivadas in vitro - Revisão de literatura. Vet. e Zootec. 2017 Set.; 24(3): 468-479.
} 


\title{
CAPACIDADAD DE LIGACIÓN DE LOS ESPERMATOZOIDES DEL EPIDÍDIMO DE EQUINOS A CÉLULAS DEL OVIDUCTO UTERINO CULTIVADOS IN VITRO - REVISIÓN DE LITERATURA
}

\begin{abstract}
RESUMEN
Muchas biotecnologías desarrolladas actualmente son direccionadas a la conservación del material genético de garañones de alto valor zootécnico. Dentro de estas se destacan la colecta de espermatozoides de epidídimo de animales que sufrieron algún trauma o enfermedad que imposibilita la colecta de semen, y de animales que murieron o fueron eutanasiados. Las células espermáticas del epidídimo no entran en contacto con el plasma seminal, importante porque contiene proteínas que participan en procesos relacionados con la protección y ligación de los espermatozoides al reservorio espermático en el oviducto uterino. En este sentido, se sugiere que existen importantes alteraciones bioquímicas en las células espermáticas del epidídimo, por tanto el motivo de esta revisión es estudiar las principales diferencias morfo funcionales entre los espermatozoides provenientes del epidídimo y los provenientes del eyaculado en caballos.
\end{abstract}

Plalabras claves: espermatozoide, plasma seminal, adhesión celular.

\section{INTRODUÇÃO}

De acordo com o Instituto Brasileiro de Geografia e Estatística (1), o Brasil conta com o quarto maior rebanho equino do mundo, com um plantel de 5,5 milhões de cabeças, o segundo maior rebanho bovino com um efetivo nacional de $\mathbf{2 1 2 , 8}$ milhões de cabeças, além de um crescimento considerável no rebanho dos animais de médio porte como caprinos, ovinos e suínos ( 9,17 e 39 milhões de cabeças, respectivamente), sendo um dos países que mais gera produtos utilizando biotécnicas reprodutivas.

Esta produção tem estimulado o desenvolvimento de biotecnologias da reprodução visando a conservação de material genético de animais de alto valor zootécnico. Dentre estas, pode ser destacar a colheita de espermatozoides do epidídimo de reprodutores que sofreram algum trauma ou enfermidade que impossibilitem a colheita do sêmen, ou que tenham vindo a óbito ou eutanásia. Nestes casos, muitos proprietários têm buscado uma última recuperação do sêmen na tentativa de obter mais produtos com a genética valiosa daqueles animais.

Embora estudos recentes em equinos demonstrem um avanço significativo no que se refere à viabilidade dos espermatozoides recuperados da cauda do epidídimo, os componentes moleculares dos espermatozoides, ou dos meios que os cercam, influenciam na capacidade de fertilização destas células. Frente a tal conceito, proteínas do plasma seminal modulam funções e processos cruciais da reprodução, como a motilidade, capacitação espermática, proteção celular, reação acrossômica e fertilização.

É conhecido que ao entrar em contato com o plasma seminal, os espermatozoides adquirem a capacidade de se aderir aos sítios de ligação dos reservatórios espermáticos na tuba uterina, pela combinação de uma série de fatores. Dentre estes, o edema da mucosa da tuba uterina associado à fase do ciclo estral levando a constrição localizada do istmo, redução da motilidade espermática no istmo, retenção dos espermatozoides no muco local e fixação às células epiteliais da tuba uterina (2).

In vitro, o reservatório espermático aumenta a viabilidade do espermatozoide equino (3). Pesquisas demonstraram que o reservatório espermático possui diferentes funções como a prevenção da capacitação espermática precoce, por manter em nível basal a concentração

Carneiro JAM, Cruz RKS, Souza FF, Dell'Aqua Junior JA. Capacidade de ligação dos espermatozoides do epidídimo de equinos às células da tuba uterina cultivadas in vitro - Revisão de literatura. Vet. e Zootec. 2017 Set.; 24(3): 468-479. 
intracelular de cálcio e redução do risco de poliespermia por liberar uma quantidade pequena e suficiente de espermatozoides para a fecundação no momento da ovulação (4).

Porém a inseminação artificial com espermatozoides da cauda do epidídimo, os gametas não entraram em contato com o plasma seminal, podendo assim não adquirir essa capacidade de fixação no sítio de ligação na tuba uterina.

Embora os dados sobre as características de vários componentes bioquímicos do plasma seminal tenham sido publicados e progressos feitos especialmente no campo da proteômica, pouco se sabe a respeito da diferença de adesão dos espermatozoides provenientes do epidídimo e do ejaculado nos sítios de ligação dos reservatórios espermáticos, e até onde o plasma seminal é responsável por essa relação, na espécie equina.

Com base nessas informações e para melhor compreensão da fisiologia espermática, objetivou-se com essa revisão discorrer sobre a importância do plasma seminal e seus principais componentes, como é realizado o transporte espermático, identificar as principais diferenças morfofuncionais entre os espermatozoides provenientes do ejaculado $\mathrm{e}$ do epidídimo, assim como sua interação nos sítios de ligação do reservatório espermático no oviduto.

\section{Plasma seminal e seus principais componentes}

O sêmen é composto por duas frações distintas: os espermatozoides, que compõem menos que $1 \%$ do volume total e o plasma seminal. O plasma seminal é uma mistura de fluido segregado a partir dos testículos, epidídimos e glândulas acessórias, responsável uma infinidade de funções e eventos que precedem a fecundação. Ao entrar em contato com o plasma seminal, os espermatozoides são revestidos com proteínas, enzimas, hormônios e íons secretados pelas glândulas sexuais acessórias do macho (5).

A maioria das proteínas presentes no plasma seminal é proveniente do epidídimo e estão envolvidas na remodelação da membrana espermática, que ocorre durante o trânsito epididimário e após a ejaculação (6).

As proteínas são classificadas de acordo com o tipo de interação com a célula espermática. Podem ocorrer ligações fracas, responsáveis pela quiescência dos espermatozoides; ligações fortes, importantes no trato reprodutivo da fêmea e na fertilização; modificações das proteínas da membrana plasmática, encobrindo ou expondo receptores; ou presença de proteínas livres no fluido epididimário, colaborando com a manutenção do meio (7).

Até o momento, sabe-se que a maioria das proteínas seminais pertence a três grupos: as proteínas transportadoras de dois ou quatro módulos de fibronectina tipo II (Fn-2), proteínas secretórias ricas em cisteína (CRISPs), e as espermadesinas (8).

As proteínas do grupo Fn-2 apresentam número variável de domínios de fibronectina do tipo II e estão presentes ao longo de todo o trato reprodutivo masculino, sendo expressas no corpo, cauda do epidídimo e na ampola do ducto deferente. Essas proteínas interagem especificamente com fosfatidilcolina da membrana plasmática do espermatozoide no momento da ejaculação e possuem habilidade de se ligar à heparina (9).

As proteínas HSP-1 e HSP-2 representam 70-80\% das proteínas totais do plasma seminal equino e pertencem ao grupo das proteínas Fn-2, sendo caracterizadas pela habilidade de ligação à heparina (9).

O segundo grupo de proteínas importantes é representado pelas CRISP. Este grupo é caracterizado por apresentar 16 resíduos de cisteína em sua estrutura molecular e são divididas em CRISP1, CRISP2 e CRISP3. A CRISP 1 é expressa ao longo do epidídimo, enquanto a CRISP 2 é expressa no testículo, epidídimo e glândulas vesiculares (10).

Carneiro JAM, Cruz RKS, Souza FF, Dell'Aqua Junior JA. Capacidade de ligação dos espermatozoides do epidídimo de equinos às células da tuba uterina cultivadas in vitro - Revisão de literatura. Vet. e Zootec. 2017 Set.; 24(3): 468-479. 
Em maior quantidade, proteínas da classe CRISP 3 são expressas desde o epidídimo até o resto do trato genital, com maior expressão na ampola do ducto deferente. As CRISPs são expressas sob controle androgênico e ligam-se na região equatorial, pós-acrossomal e na peça intermediária dos espermatozoides, estando intimamente relacionadas com a fusão do espermatozoide ao oócito. A proteína HSP-3 pertence ao grupo CRISP, sendo estruturalmente semelhante às proteínas deste grupo (11).

As espermadesinas possuem de 110 a 113 aminoácidos na sua estrutura e compreendem um único domínio CUB (domínio proteico) estabilizado por pontes dissulfídicas. Estas proteínas são multifuncionais e exibem habilidade para se ligar à heparina, a inibidores de proteinase, fosfolipídeos e carboidratos (10).

A HSP-7 é a maior representante das espermatodesinas em garanhões, e é secretada durante o trajeto do espermatozoide pelo ducto epididimário. Esta possui papel importante na interação espermatozoide-zona pelúcida (12).

A osteopontina identificada e isolada da matriz óssea bovina, cartilagens, pele fetal, cérebro, rins, ovários, útero, bem como da urina, bile e leite bovino, e também secretadas pelo plasma seminal (13). No trato reprodutivo masculino, essa proteína é expressa nas células epiteliais das ampolas e glândulas vesiculares, em espermátides alongadas nos testículos, além do epidídimo e em espermatozoides epididimários (14).

Embora as proteínas contidas no plasma seminal exerçam papel importante na funcionalidade dos espermatozoides, existe a hipótese de que o plasma não seja totalmente essencial à fertilização, ou até mesmo danifica os espermatozoides (15). Esta hipótese é sustentada pelos estudos que demonstraram ser possível fecundar os oócitos com espermatozoides epididimais e mesmo células espermáticas primordiais (16).

\section{Transporte espermático}

Logo após a cobertura, ou a inseminação artificial, o útero se torna um ambiente hostil para os espermatozoides devido à ocorrência de uma reação inflamatória contra as bactérias e o sêmen. Assim, o transporte rápido é extremamente importante para que os espermatozoides alcancem a tuba uterina e possam fertilizar o oócito (3).

A duração do transporte espermático depende do intervalo entre a inseminação e a ovulação e da meia-vida funcional do espermatozoide no trato utterino da fêmea (17). As contrações musculares do trato reprodutivo, os movimentos ciliares, a corrente de fluido e a atividade flagelar dos espermatozoides constituem os mecanismos primários do transporte espermático (18).

Scott et al. (19) descreveram a presença de espermatozoide no lúmen da junção úterotubárica, 18 e 26 horas após a inseminação artificial com sêmen fresco. Os autores concluíram que a junção uterotubárica também faz parte do reservatório espermático na égua.

Bader (20) realizou um estudo em que as éguas foram eutanasiadas 2, 4 e 6 horas após a inseminação, sendo realizados lavados da junção úterotubárica, istmo e ampola da tuba uterina ipsilateral à ovulação. O número de espermatozoides na junção uterotubárica e tuba uterina foi superior 4 horas após a inseminação, quando comparado a 2 e 6 horas.

A habilidade dos espermatozoides congelados ascenderem a tuba uterina e alcançarem à ampola é muito menor que as células a fresco. Estudos indicam que embora poucos espermatozoides estejam presentes na junção uterotubárica e istmo após 2 horas da inseminação, o transporte até a ampola ainda não se completou, evento observado após 4 horas (21).

Após o transporte até a tuba, os espermatozoides se aderem às células do epitélio tubárico formando o reservatório espermático. Nos equinos o reservatório se forma no istmo da tuba uterina até quatro horas após a monta ou inseminação artificial (20). 


\section{Espermatozoides provenientes do epidídimo $\mathrm{x}$ ejaculado}

Em gatos, a gota citoplasmática distal foi o defeito mais frequente em espermatozoides provenientes da cauda do epidídimo e provavelmente está relacionado ao processo de maturação espermática durante sua passagem pelo epidídimo. Sendo que o espermatozoide irá perder este resquício citoplasmático durante a ejaculação (22).

Foi verificado por Yu e Leibo (23), na espécie canina, que após 6 horas da orquiectomia, a integridade da membrana do espermatozoide a fresco foi de 70 a $80 \%$. Após 48 horas, mais de $70 \%$ das células recuperadas do epidídimo refrigerado apresentavam membrana intacta, valores semelhantes ao do ejaculado. Em contraste, foi observado que a motilidade espermática diminuiu significativamente nas primeiras 5 horas de refrigeração, após esse período o decréscimo foi mais lento.

De acordo com Johnston et al. (24), a concentração de espermatozoides recuperados do epidídimo de cães é semelhante a concentração espermática descrita para o ejaculado.

Os espermatozoides armazenados no epidídimo bovino possuem a capacidade de fecundar o oócito, entretanto, o plasma seminal possui fatores decapacitantes, o que promovem alterações metabólicas e bioquímicas em sua estrutura, contribuindo com a capacitação e reação do acrossomo $(25,26)$. Apesar disto, Amann e Griel-Jr. (27), também trabalhando com bovinos, mostraram que espermatozoides da cauda do epidídimo possuem capacidade de fertilização similar ao do ejaculado.

Santos e Vannucchi (28), relacionaram a baixa motilidade e vigor espermático da célula epididimária descongelada à imaturidade da célula espermática bovina. Entretanto, apesar de Martins et al. (29) também terem detectado uma queda significativa da motilidade espermática após a descongelação do sêmen bovino, a porcentagem de células íntegras e a porcentagem de células morfologicamente normais foram semelhantes aos resultados obtidos na descongelação de espermatozoides obtidos de ejaculados e do epidídimo.

Estudos realizados por Silva et al. (30) mostraram que a motilidade (50 a 90\%) e vigor espermático do ejaculado foi maior do que a dos espermatozoides do epidídimo (20 a 70\%), respectivamente. Diferença essa que poderia ser atribuída a imaturidade da célula espermática proveniente da cauda do epidídimo. Não foram observadas diferenças significativas quanto aos defeitos morfológicos, integridade do acrossômo e da cromatina entre os dois grupos.

Em muares, Glória et al. (31) observaram diferenças significativas na viabilidade $(90,9$ $\pm 3,7 \%$ em espermatozoides do epidídimo e $71,7 \pm 6,1 \%$ no ejaculado) e atividade mitocondrial $(85,7 \pm 3,1 \%$ e $77,6 \pm 2,6 \%$ em espermatozoides do epidídimo e ejaculado, respectivamente), embora valores de motilidade total e progressiva tenham sido semelhantes, tanto para espermatozoides epididimários quanto para o ejaculado.

Em equinos, Monteiro et al. (32) observaram que o número médio de espermatozoides obtidos do ejaculado (colhidos com vagina artificial) e da cauda do epidídimo foi, respectivamente: 6,9 e 20,4 $\times 10^{9}$. Estes resultados são semelhantes a achados anteriores, nos quais o número total de espermatozoides recuperados da cauda do epidídimo foi superior aos colhidos com vagina artificial (33- 35). Os parâmetros motilidade e velocidade dos espermatozoides do epidídimo foram superiores aos espermatozoides do ejaculado (32).

Aurich et al. (36) demonstrou efeito deletério na viabilidade espermática com a adição do plasma seminal proveniente de garanhões de baixa congelabilidade. Além disso, outros estudos demonstraram que proteínas contidas no plasma seminal podem promover alterações bioquímicas, levando a danos na membrana plasmática com prejuízos na fertilidade e congelabilidade espermática $(37,38)$.

Monteiro et al. (32) observaram maior porcentagem de defeitos morfológicos de cauda e defeitos totais nos espermatozoides do ejaculado quando comparado com espermatozoides da

Carneiro JAM, Cruz RKS, Souza FF, Dell'Aqua Junior JA. Capacidade de ligação dos espermatozoides do epidídimo de equinos às células da tuba uterina cultivadas in vitro - Revisão de literatura. Vet. e Zootec. 2017 Set.; 24(3): 468-479. 
cauda do epidídimo de garanhões. Estes achados diferem de resultados obtidos por Monteiro (35) em que não houve diferença na morfologia espermática entre espermatozoides do epidídimo e do ejaculado, além de estudos realizados em bovinos por Silva et al. (30) e Martins et al. (39), que detectaram maior frequência de gota protoplasmática em amostras do epidídimo quando confrontadas com o sêmen do ejaculado.

\section{Reservatório espermático na tuba uterina}

A tuba uterina consiste de três segmentos, cada um com diferentes funções: istmo, ampola e infundíbulo. $\mathrm{O}$ istmo possui a função de armazenamento espermático, a ampola proporciona um ambiente favorável a fertilização e ao desenvolvimento embrionário inicial e o infundíbulo possui fimbrias para captação do oócito. A tuba uterina comunica-se com o útero pela junção uterotubárica que proporciona uma barreira aos micro-organismos patogênicos que possam invadir a tuba uterina a partir do útero, além de regular a passagem do espermatozoide (40).

As células espermáticas ficam retidas no reservatório espermático da tuba uterina pela combinação de inúmeros fatores. Dentre estes uma constrição localizada no istmo em vista do edema da mucosa da tuba uterina associado à fase do ciclo estral, fazendo com que haja a queda da motilidade espermática neste local. Assim como aprisionamento dos espermatozoides no muco local e fixação às células epiteliais da tuba uterina (2).

A incubação in vitro com células do reservatório espermático aumenta a viabilidade do espermatozoide equino (3). In vivo, pesquisas demonstraram que o reservatório espermático possui diferentes funções como prevenção da capacitação espermática precoce, por manter em nível basal a concentração intracelular de cálcio. Assim como a redução do risco de poliespermia por liberar uma quantidade pequena e suficiente de espermatozoides para a fecundação no momento da ovulação (4).

Análise por micrografia eletrônica demonstrou que os espermatozoides se ligam às células ciliadas e não ciliadas, sendo que as células epiteliais do istmo apresentaram maior número de espermatozoides fixados quando comparadas às da ampola. Maior número de espermatozoides se liga ao epitélio da tuba uterina nas fases folicular e pós-ovulação quando comparado com diestro (2).

Pesquisas relatam diferenças entre garanhões no que se refere a formação do reservatório espermático, sendo que espermatozoides proveninentes de garanhões sub-férteis possuem uma menor capacidade de adesão às células epiteliais da tuba uterina quando comparado com espermatozoides provenintes de garanhões férteis (41).

De acordo com Katila et al. (42) protocolos de criopreservação do sêmen equino causam danos subletais ao espermatozoide o qual prejudica a formação do reservatório espermático. Assim sendo, a criopreservação leva a uma diminuição no número de espermatozoides aderido as células da tuba uterina após a inseminação, como também uma diminuição do tempo de sobrevivência destes gametas, necessitando de precisão no que se refere ao momento da inseminação.

Nos bovinos, a ligação dos espermatozoides do epidídimo ao epitélio da tuba uterina ocorre em um nível baixo, porém quando acrescido das proteínas BSPs (A1 e A2) purificadas, a partir do plasma seminal, a ligação aumenta para níveis comparados com o do ejaculado (43).

Receptores para as proteínas BSPs na tuba uterina bovina foram isolados a partir de extratos do epitélio da membrana apical utilizando proteínas purificadas BSPs como armadilhas. Os receptores foram identificados como sendo quatro membros da família das proteínas anexinas (ANXA1, -2, -4, -5) sendo fortes candidatos para os receptores de espermatozoides no epitélio da tuba uterina bovina (44).

Carneiro JAM, Cruz RKS, Souza FF, Dell'Aqua Junior JA. Capacidade de ligação dos espermatozoides do epidídimo de equinos às células da tuba uterina cultivadas in vitro - Revisão de literatura. Vet. e Zootec. 2017 Set.; 24(3): 468-479. 
ANXAs compreendem uma grande família de proteínas cujas funções são mal compreendidas. Tais proteínas foram localizadas no interior das células epiteliais da tuba uterina, em secreções e na superfície destas. Cada receptor ANXA isoladamente é suficiente para elevar a ligação do espermatozoide com o epitélio da tuba uetrina a valores semelhantes ao do ejaculado, sendo improvável que elas sejam necessárias em conjunto como um complexo (45).

ANXA1 é secretada pela próstata humana em quantidades elevadas no plasma seminal. Contudo, se desconhece se o espermatozoide humano transporta as ANXAs do plasma seminal até a tuba uterina, onde estas podem ser substituídas por ANXAs do epitélio. Considerando que BSPs, individualmente, melhoram a ligação do espermatozoide ao epitélio da tuba uterina, não se conhece se cada ANXA pode atuar como um receptor independente para o espermatozoide (46).

As proteínas BSP diferem umas das outras na distribuição de carga eletrostática da superfície. Esta propriedade confere as BSPs diferentes afinidades de ligação de uma molécula na superfície do espermatozoide com a molécula oposta no epitélio tubárico. Do mesmo modo, as várias ANXAs presentes na tuba uterina devem ter diferentes afinidades de ligação e cinética com as BSPs espermáticas (47).

Assim, a interação entre as BSPs espermáticas e as ANXAs da tuba uterina pode fornecer um sistema regulatório para assegurar que células espermáticas sejam mantidas férteis no reservatório e sejam gradualmente liberadas no momento apropriado para assegurar a fertilização (48).

A ligação do espermatozoide ao epitélio de alguma forma preserva sua fertilidade durante o armazenamento. $\mathrm{O}$ espermatozoide aderido ao epitélio da tuba uterina mantém baixos níveis de $\mathrm{Ca}^{2+}$ citoplasmático, em comparação aos espermatozoides com movimentação livre $(49,50)$.

O mecanismo para a prevenção do aumento de $\mathrm{Ca}^{2+}$ citoplasmático em espermatozoides não é totalmente elucidado, mas sugere-se que a catalase, presente na tuba uterina bovina, serve para minimizar os danos peroxidativos às membranas dos espermatozoides, impedindo o influxo de $\mathrm{Ca}^{2+}$ para a célula (51).

Em um sistema de co-cultivo heterólogo (Figura $1 \mathrm{a}, \mathrm{b}, \mathrm{c}$ e d) entre espermatozoides de garanhões e células do epitélio tubárico bovino, foi observada a adesão das células espermática às células da tuba uterina, ocorrendo o aumento da sobrevivência dos espermatozoides, in vitro. Resultado semelhante ao que foi observado em sistema de cocultivo espermatozoide-explants da mesma espécie $(52,53)$.

Carneiro JAM, Cruz RKS, Souza FF, Dell'Aqua Junior JA. Capacidade de ligação dos espermatozoides do epidídimo de equinos às células da tuba uterina cultivadas in vitro - Revisão de literatura. Vet. e Zootec. 2017 Set.; 24(3): 468-479. 

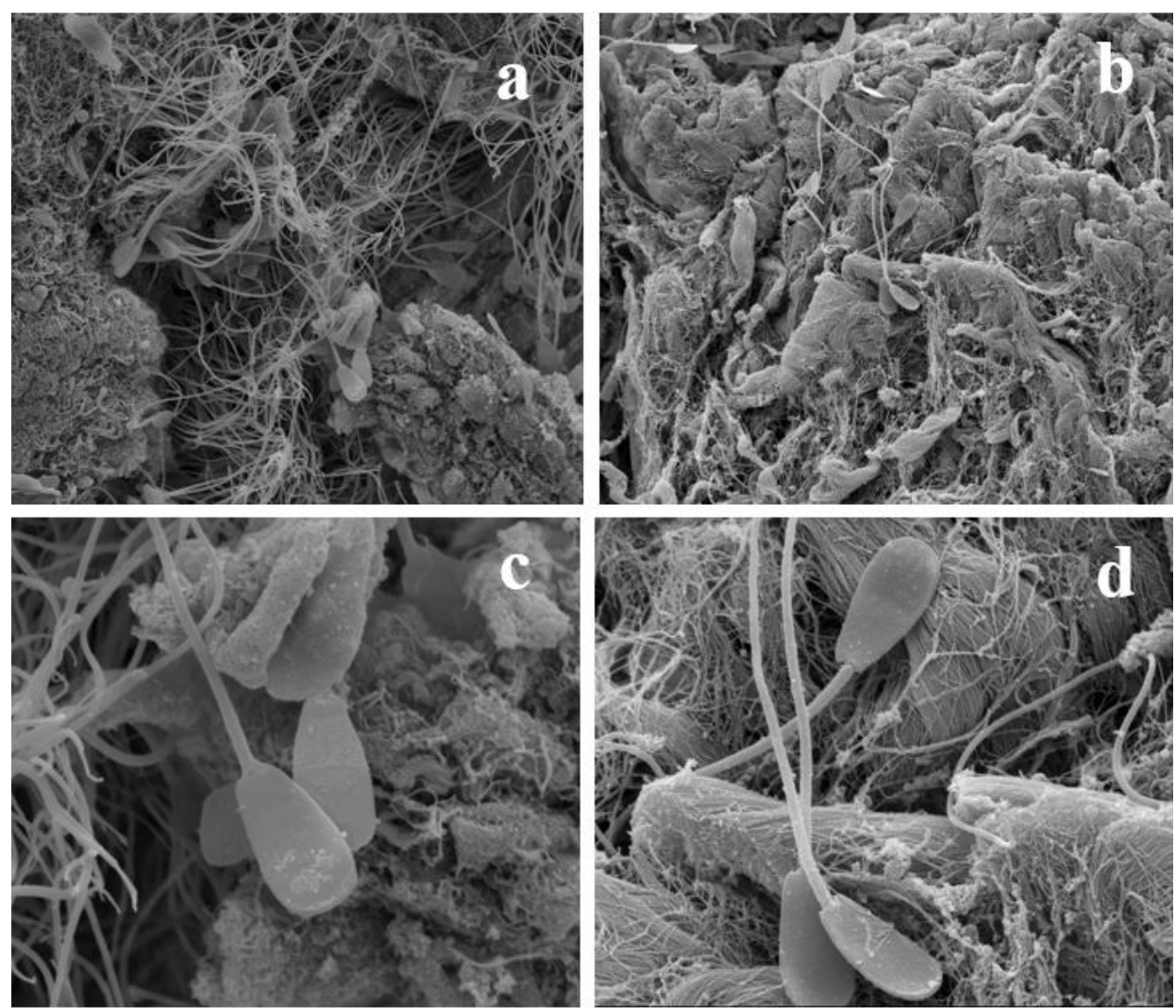

Figura 1. Microscopia eletrônica de varredura de células epiteliais da tuba uterina bovina 30 min após a adição de espermatozoides equinos. (a) Vista da interação espermatozoide - explant da tuba uterina (× 2550) (b) Outra vista da interação espermatozoide - explant da tuba uterina $(\times 3180)$. (c e d) Ampliação dos cultivos a e b, respectivamente, em que os espermatozoides podem ser vistos em contato com a células epiteliais da tuba uterina $(\mathrm{c} ; \times 10000)(\mathrm{d} ; \times 8760)$. Podemos notar a presença dos cílios entorno das células espermáticas.

Embora as lecitinas que intermediam a ligação entre o espermatozoide e as células do epitélio tubárico sejam diferentes entre bovinos e equinos, foi constatada uma adesão celular com subsequente prolongamento na viabilidade espermática em sistema de co-cultivo, o que comprova a viabilidade da utilização da técnica entre espécies diferentes (52).

\section{CONSIDERAÇÕES FINAIS}

Apesar do seu incompleto desenvolvimento funcional, as células germinativas da cauda do epidídimo são capazes de desempenhar sua função de forma efetiva.

Com a melhoria dos extensores e dos métodos de colheita de células espermáticas da cauda do epidídimo, se tornou possível a utilização deste tipo celular na fertilização de oócitos de várias espécies animais, o que é de suma importância, pois aumenta a possibilidade de preservação do germoplasmas.

\section{REFERÊNCIAS}

1. Instituto Brasileiro e Geografia e Estatística. Produção da pecuária nacional, 2011 [Internet]. Rio de Janeiro: IBGE; 2011 [cited 2015 Dez 18]. Available from: http://www.ibge.gov.br/home/presidencia/noticias/noticia_visualiza.php?id_noticia=2241 \&id_pagina=1 
2. Thomas PGA, Ball BA, Brinsko SP. Interaction of equine spermatozoa with oviduct epithelial cell explants is affected by estrous cycle and anatomic origin of explant. Biol Reprod. 1994;51:222-8.

3. Troedsson MHT, Liu IKM, Crabo BG. Sperm transport and survival in the mare. Theriogenology. 1998;49:905-15.

4. Lefebvre R. Characterization of the oviductal sperm reservoir in cattle. Biol Reprod. 1995;53:1066-74.

5. Wite RG. Secreções do trato reprodutivo masculino e plasma seminal. In: Hafez ESE. Reprodução animal. 4a ed. São Paulo: Manole; 1988. p.212-28.

6. Dacheux JL, Gatti JL, Dacheux F. Contribution of epididymal secretory proteins for spermatozoa maturation. Microsc Res Tech. 2003;61:7-17.

7. Marengo SR. Maturing the sperm: unique mechanisms for modifying integral proteins in the sperm plasma membrane. Anim Reprod Sci. 2008;105:52-63.

8. Kareskoski M, Katila T. Components of stallion seminal plasma and the effects of seminal plasma on sperm longevity. Anim Reprod Sci. 2008;107:249-56.

9. Ekhalasi-Hundrieser M, Schafer B, Kirchhof C, Hess O, Bellair S, Müller P. Structural and molecular characterization of equine sperm-binding fibronectin-II module proteins. Mol Reprod Dev. 2005;70:45-57.

10. Töpfer-Petersen E, Ekhlasi-Hundrieser M, Kirchhoff C, Leeb T, Sieme H. The role of stallion seminal proteins in fertilization. Anim Reprod Sci. 2005;89:159-70.

11. Schambony A, Hess O, Gentzel M, Töpfer-Petersen E. Expression of CRISP proteins in the male equine genital tract. J Reprod Fertil. 1998;53:67-72.

12. Reinert M, Calvete JJ, Sanz L, Mann K, Töpfer-Petersen E. Primary structure of stallion seminal plasma protein HSP-7, a zona-pellucida-binding protein of the spermadhesin family. Eur J Biochem. 1996;242:636-40.

13. Sorensen ES, Petersen TE. Purification and characterization of three proteins isolated from the proteose peptone fraction of bovine milk. J Dairy Res. 1993;60:189-97.

14. Rodríguez CM, Day JR, Killian GJ. Expression of the lipocalin-type prostaglandin D synthase gene in the reproductive tracts of Holstein bulls. J Reprod Fertil. 2000;120:3039.

15. Al-Somai N, Vishwanath R, Molan PC. Anionic and cationic components from protein aggregates in bovine seminal plasma and their effects on sperm motility. Mol Reprod Dev. 1994;39:328-36.

16. Martins CF, Silva AEDF, Matarazzo R. Evaluation of the quality of cryopreserved bovine epididimal spermatozoa by analysis of motility, acrossomal status, penetration ability in oocytes and integrity of sperm chromatin. Biol Reprod. 2000;62:156. 
17. Scott MA. A glimpse at sperm function in vivo: sperm transport and epithelial interaction in the female reproductive tract. Anim Reprod Sci. 2000;60-61:337-48.

18. Hunter RHF. Sperm transport and reservoirs in the pig oviduct in relation to the time of ovulation. J Reprod Fertil. 1981;63:109-17.

19. Scott MA, Varner DD, Liu IKM, Enders AC. Presumptive evidence of a preovulatory sperm reservoir in the mare: morphological investigations using scanning electron microscopy. Theriogenology. 2002;58:639-42.

20. Bader HA. An investigation of sperm migration into the oviducts of the mare. J Reprod Fertil. 1982;32:59-64.

21. Scaldelai PRR, Bertozzo BR, Shiroma MYM, Castro JB, Zúccari CESN. Aspectos relacionados ao uso do sêmen congelado de garanhões. Vet Foco. 2010;7:108-23.

22. Axnér E, Ström-Holst B, Linde-Forsberg C. Morphology of spermatozoa in the cauda epididymisbefore and after electroejaculation and a comparison with ejaculated spermatozoa in the domestic cat. Theriogenology. 1998;50:973-9.

23. Yu I, Leibo SP. Recovery of motile, membrane-intact spermatozoa from canine epididymides stored for 8 days at $4^{\circ} \mathrm{C}$. Theriogenology. 2002;57:1179-90.

24. Johnston SD, Kustritz MVR, Oslon PNS. Semen collection, evaluation and preservation. In: Johnston SD, Kustritz MVR, Oslon PNS. Canine and feline theriogenology. Philadelphia: WB Saunders; 2001. p.287-306.

25. Yang X, Jiang S, Foote RH. Bovine oocyte development following different oocyte maturation and sperm capacitation procedures. Mol Reprod Dev. 1993;34:94-100.

26. Yanagimachi R. Mammalian fertilization. In: Knobil E, Neil JD. The physiology of the reproduction. 2a ed. New York: Raven Press; 1994. p.189-317.

27. Amann RP, Griel-Jr LC. Fertility of bovine spermatozoa from rete testis, cauda epididymidis and ejaculated sperm. J Dairy Sci. 1974;57:212-9.

28. Santos SEC, Vannucchi CI. Criopreservação de espermatozoides epididimários em cães pós-mortem. Rev Bras Reprod Anim. 2002;26:129-276.

29. Martins MIM, Souza FF, Chirinéa VH, Tebet J, Lopes MD. Viabilidade de espermatozoides criopreservados, obtidos do epidídimo de cães. In: Mostra Científica da FMVZ/UNESP; 2003; Botucatu. Botucatu: Universidade Estadual Paulista; 2003.

30. Silva AEDF, Dias AL, Unanian MM, Freitas AR, Junior CB. Conteúdo de peptídeos e avaliação morfofisiológica dos espermatozoides do epidídimo e ejaculado de bovinos. Rev Bras Zootec. 2003;32:1890-900.

31. Gloria A, Contri A, Amicis ID, Robbe D, Carluccio A. Differences between epididymal and ejaculated sperm characteristics in donkey. Anim Reprod Sci. 2011;128:117-22. 
32. Monteiro GA, Papa FO, Guast PN, Freitas NPP, Melo CM, Avanzi BR, et al. Fertilidade de espermatozoides recuperados da cauda do epidídimo de garanhões subférteis. Vet Zootec. 2011;18:255-63.

33. Muradás PR, Weiss RR, Kozicki LE, Granemann LC, Santos IW, Pimpão CT. Alguns parâmetros de viabilidade de espermatozoides equinos colhidos por vagina artificial e por lavagem da cauda do epidídimo. Arch Vet Sci. 2006;11:69-74.

34. Granemann LC. Avaliação comparativa do sêmen eqüino colhido com vagina artificial e por lavado intraluminal da cauda do epidídimo pós-orquiectomia [dissertação]. Curitiba: Universidade Federal do Paraná; 2006.

35. Monteiro GA. Criopreservação e fertilidade de espermatozoides recuperados da cauda do epidídimo de garanhões [dissertação]. Botucatu: Faculdade de Medicina Veterinária e Zootecnia, Universidade Estadual Paulista; 2010.

36. Aurich JE, Kühne A, Hoppe H, Aurich C. Seminal plasma affects membrane integrity and motility of equine spermatozoa after cryopreservation. Theriogenology. 1996;46:7917.

37. Moore HDM, Hibbit KCS. The binding of labeled basic proteins by boar spermatozoa. J Reprod Fertil. 1976;46:71-7.

38. Moustafa AR, Mezaros I. Interrelationship between the total protein content of bovine seminal plasma and behavior of spermatozoa after freezing-and-thawing. Acta Vet Acad Sci Hung. 1981;28:403-8.

39. Martins CF, Rumpf R, Pereira DC, Dode MN. Cryopreservation of epididymal bovine spermatozoa from dead animals and its uses in vitro embryo production. Anim Reprod Sci. 2007;101:326-31.

40. Suarez SS. Regulation of sperm storage and movement in the mammalian oviduct. Int $\mathbf{J}$ Dev Biol. 2008;52:455-62.

41. Scott MA, Liu IK, Overstreet JW. Sperm transport to the oviducts: abnormalities and their clinical implications. In: Proccedings of the 41o Annual Convention - American Association of Equine Practitioner; 1995; Lexington. Lexington: AAEP; 1995. p.1-2.

42. Katila T, Celebi M, Koskinen E. Effect of timing of frozen semen insemination on pregnancy rate in mares. Acta Vet Scand. 1996;37:361-5.

43. Gwathmey TM, Ignotz GG, Mueller JL, Manjunath P, Suarez SS. Bovine seminal plasma proteins PDC-109, BSP-A3, and BSP-30-kDa share functional roles in storing sperm in the oviduct. Biol Reprod. 2006;75:501-7.

44. Ignotz GG, Cho MY, Suarez SS. Annexins are candidate oviductal receptors for bovine sperm surface proteins and thus may serve to hold bovine sperm in the oviductal reservoir. Biol Reprod. 2007;77:906-13. 
45. Rescher U, Gerke V. Family, friends and functions. Pflugers Arch. 2008;455:575-82.

46. Christmas P, Callaway J, Fallon J, Jones J, Haigler HT. Selective secretion of annexin 1, a protein without a signal sequence, by the human prostate gland. J Biol Chem. 1991;266:2499-507.

47. Gwathmey TM, Ignotz GG, Suarez SS. PDC-109 (BSP-A1/ A2) promotes bull sperm binding to oviductal epithelium in vitro and may be involved in forming the oviductal sperm reservoir. Biol Reprod. 2003;69:809-15.

48. Fan J, Lefebvre J, Manjunath P. Bovine seminal plasma proteins and their relatives: a new expanding superfamily in mammals. Gene. 2006;375:63-74.

49. Dobrinski I, Suárez SS, Ball BA. Intracellular calcium concentration in equine spermatozoa attached to oviductal epithelial cells in vitro. Biol Reprod. 1996;54:783-8.

50. Dobrinski I, Smith TT, Suárez SS, Ball BA. Membrane contact with oviductal epithelium modulates the intracellular calcium concentration of equine spermatozoa in vitro. Biol Reprod. 1997;56:861-9.

51. Lapointe S, Sullivan R, Sirard MA. Binding of a bovine oviductal fluid catalase to mammalian sperm. Biol Reprod. 1998;58:747-53.

52. Samper J, Ellington J, Burnett K, Jones A, Wright R. Use of sperm and oviduct cell coculture as a test for stallion field fertility. In: Proccedings of the 41o Annual Convention American Association of Equine Practitioner; 1995; Lexington. Lexington: AAEP; 1995. p.3-5.

53. Ellington JE, Jones AE, Davitt CM, Schneider CS, Brisbois RS, Hiss GA, et al. Human sperm function in co-culture with human, macaque or bovine oviduct epithelial cell monolayers. Hum Reprod. 1998;13:2797-804.

Recebido em: 04/09/2016

Aceito em: 13/07/2017

Carneiro JAM, Cruz RKS, Souza FF, Dell'Aqua Junior JA. Capacidade de ligação dos espermatozoides do epidídimo de equinos às células da tuba uterina cultivadas in vitro - Revisão de literatura. Vet. e Zootec. 2017 Set.; 24(3): 468-479. 